\title{
Sources of Productivity Growth in rainbow Trout Aquaculture in Iran: Technical Efficiency Change or Technological Progress?
}

\begin{abstract}
This study investigates the sources of total factor productivity (TFP) growth in rainbow trout production in Iran using data envelopment analysis (DEA). The Malmquist index is then employed to decompose the TFP growth into technical efficiency change and technological progress. We utilized panel data of 207 trout farms in the country over a 5-year period from 2003 to 2007. The results of this study revealed that TFP growth of rainbow trout farming has an increasing trend over the period at an average annual rate of $3.7 \%$. The trend of cumulative technological change is negative and tends to be contrary to cumulative technical efficiency change. Although there is no technological change or innovation on trout farming, the technical efficiency change was found to be the sole source for TFP change, whereas the mean of technical efficiency was estimated to be about $66 \%$. Therefore, there is still a great relative potential for increasing trout production through improvement in managerial efficiency as well as technological progress. The study suggests that Iran also has considerable room to enhance trout aquaculture's TFP growth by shifting the production frontier with adoption of new technologies and improving innovation.
\end{abstract}

Keyword: DEA, Malmquist index, rainbow trout, technical efficiency, technological changes, TFP growth 